\title{
Ambient moisture causes methomyl residues on corn plants to rapidly lose toxicity to the pest slug, Arion subfuscus, Müller (Gastropoda, Stylommatophora)
}

\author{
Louis B. Nottingham *, Thomas P. Kuhar \\ Virginia Tech, Department of Entomology, 170 Drillfield Drive, Blacksburg, VA, 24061, USA
}

\section{A R T I C L E I N F O}

\section{Keywords:}

Slug

Methomyl

Toxicity

Field crop

Insecticide

\begin{abstract}
A B S T R A C T
The carbamate insecticide methomyl is sometimes used to control slugs in field corn and soybean by foliar applications, but control outcomes in research trials and commercial operations have been mixed. In this study, laboratory bioassays were conducted on dusky slug, Arion subfuscus Müller, a common pest of corn and soybean in the Mid-Atlantic United States, to evaluate residual toxicity of Lannate LV (methomyl) at low and high concentrations corresponding to label recommended field rates, and if toxicity may be affected by ambient moisture or repellency to treated plants. Without wetting events, methomyl residues on corn plants caused 90-100\% mortality of $A$. subfuscus for two days and 70-90\% mortality for six days. When corn plants were briefly misted with ca. $0.3 \mathrm{~cm}$ of water $6 \mathrm{~h}$ after methomyl application, mortality was $36 \% 12 \mathrm{~h}$ after treatment, and 0 to $5 \% 24 \mathrm{~h}$ after treatment for both low and high rates. Repellency of $A$. subfuscus to corn plants treated with the high rate of methomyl was narrowly significant $(P=0.04)$ and low rate was not significant. These results suggest that high ambient moisture needed to elicit slug activity in the field also abates toxicity of methomyl residues, explaining why field control is usually poor despite high mortality in the lab.
\end{abstract}

\section{Introduction}

Terrestrial slugs and snails (Molluska, Gastropoda) are pests of many agricultural crops throughout the world, especially in wet climates and fields with crop residues and nutrient rich soils (Barker, 2002; Douglas and Tooker, 2012; Godan, 1983). Injury to developing field corn and soybean plants in the Mid-Atlantic United States has risen with adoption of reduced-tillage cultivation, which increases soil organic matter and debris for refugia (Douglas and Tooker, 2012; Gregory and Musick, 1976; Hammond and Stinner, 1987). Slug management often requires the use of pellet baits with molluscicides, metaldehyde or iron phosphate (Bailey, 2002); however, the cost of slug baits can be prohibitive for high acreage crops such as field corn and soybean (Douglas and Tooker, 2012). Methomyl, an IRAC group 1A (carbamate) insecticide, has been explored as a less expense alternative for controlling pest mollusks in crops (Eshra, 2014). From 2010 to 2019, a "2(ee) Recommendation", under the Federal Insecticide, Fungicide and Rodenticide Act (FIFRA), was issued to allow use of Lannate LV (29\% methomyl, Corteva Agriscience, Wilmington, DE) for controlling slugs in corn and soybean in numerous states in the Eastern U.S. A study led by Delaware Cooperative Extension from 2010 to 2013 examined the efficacy of Lannate LV against slugs in commercial corn and soybean fields. Results demonstrated that Lannate LV sprays were less effective than slug baits, and often provided no significant reduction in slug injury compared with untreated checks (Whalen et al., 2013). This agrees with a study by Judge and Kuhr (1972), finding methomyl to have high toxicity to slugs in lab bioassays but poor control in field trials. Although use of methomyl to control slugs is not currently permitted in the U.S. due to expiration of 2(ee) recommendations, regulations are subject to change.

The goals of our study were to determine if methomyl was toxic to slugs at rates specified on the Lannate LV label, and if so, identify factors preventing efficacy in the field. We conducted a series of laboratory experiments on the dusky slug, Arion subfuscus Müller, an introduced pest slug of corn and soybean in the Mid-Atlantic U.S. (Douglas and Tooker, 2012; Whalen et al., 2013). This medium to large slug (up to 15 $\mathrm{cm}$ long) can live for a year or longer and generally overwinters as immature (5-8 cm long), while adults are most common from late spring through summer (Beyer and Saari, 1978). Our experiments examined if

\footnotetext{
* Corresponding author. Washington State University, Department of Entomology, Tree Fruit Research and Extension Center, $1100 \mathrm{~N}$ Western Ave., Wenatchee, WA, 98801, USA.

E-mail address: louis.nottingham@wsu.edu (L.B. Nottingham).
} 
methomyl toxicity to $A$. subfuscus may be compromised by exposure method (topical contact vs. residue contact), concentration, ambient moisture, or repellency.

\section{Methods}

Slug collection and treatments. Experiments occurred from June through August of 2016. A. subfuscus were collected on mornings of experiments from various weeds, primarily dandelion (Asteraceae, Taraxacum) and vetch (Fabaceae, Vicia), near Blacksburg, Virginia, U.S. A. We avoided young slugs from experiments by collecting A. subfuscus greater than $4 \mathrm{~cm}$, extended, because there is evidence suggesting that larger slugs are more tolerant to toxicants (Hammond et al., 1996). Treatment solutions used for experiments were the following: 1. 'Check solution', 1.0 L water and $5.0 \mathrm{ml}$ non-ionic surfactant (Bio Surf, Loveland Products, Inc.); 2. 'Low rate solution', $0.25 \mathrm{ml}$ Lannate LV (0.07 g methomyl) in check solution; 3. 'High rate solution', $0.37 \mathrm{ml}$ Lannate LV ( $0.11 \mathrm{~g}$ methomyl) in check solution. Low rate and high rate solutions correspond to 1.18 and 1.77 L Lannate LV per hectare (16 and $24 \mathrm{fl}$. oz. per acre), respectively. Experimental solution concentrations correspond with field concentrations for spray volumes of 75.6 L per hectare (20 gallons per acre). Experiments were conducted in a greenhouse at Virginia Tech, Blacksburg, Virginia. Temperatures in the greenhouse were allowed to fluctuate between $15.6{ }^{\circ} \mathrm{C}\left(60^{\circ} \mathrm{F}\right)$ and $29.4^{\circ} \mathrm{C}\left(85^{\circ} \mathrm{F}\right)$. All experiments used field corn (Zea mays, cv. Reid's yellow dent) grown from untreated seeds.

Exposure method. The first experiment tested if A. subfuscus mortality from methomyl sprays differed when slugs were sprayed directly versus being exposed to dried residues on corn plants. We hypothesized that residues may be less toxic than direct spray exposures, which could lead to lower field mortality since slugs are primarily nocturnal. Treatments included: 1 . 'Check', exposure to the check solution by a combination of spray and residues on corn leaves; 2. 'Spray', exposure to high rate solution by topical sprays; 3 . 'Residue', exposure to high rate solution by residues on young corn leaves. Slugs were collected on 7 June 2016. Thirty A. subfuscus were used for each treatment. For the spray treatment, $A$. subfuscus were individually placed on a glass baking tray and sprayed with high rate solution using a $750 \mathrm{ml}$ aluminum spray bottle, then moved into 'recovery cups'. A recovery cup was a plastic deli cup, $12 \mathrm{~cm}$ diam and $20 \mathrm{~cm}$ tall, covered with a plastic lid modified to have a $5 \mathrm{~cm}$ diam mesh center for ventilation. Each recovery cup had 10 field corn plants, ca. $10 \mathrm{~cm}$ tall, growing in $5 \mathrm{~cm}$ of potting soil. For the residue treatment, four corn blades, ca. $5 \mathrm{~cm}$ long, were dipped and stirred in high rate solution for $4 \mathrm{~s}$, allowed to dry under a fume hood for $2 \mathrm{~h}$, then placed into each of five replicate $10 \mathrm{~cm}$ glass Petri dishes. Six A. subfuscus were added to each Petri dish for $6 \mathrm{~h}$, then moved into recovery cups. For check treatment, six A. subfuscus were put into each of five Petri dishes with a corn blade and sprayed with check solution (achieving both contact and residue exposure), then moved to recovery cups after $6 \mathrm{~h}$. For all treatments, A. subfuscus were rated alive or dead after $48 \mathrm{~h}$ in recovery cups. A slug was considered alive if it could right itself and move at least $5 \mathrm{~cm}$ within $5 \mathrm{~min}$ after being placed dorsal side down in the center of a glass Petri dish.

Residue toxicity decline. This experiment examined the decline in toxicity of methomyl residues on corn plants. Experimental arenas were established using the same construction as recovery cups described above. The experiment was a three by five factorial; treatments included combinations of each of three solutions (check, high rate, and low rate) with each of four time intervals after treatment $(12,24,48$, and $96 \mathrm{~h}$ after treatment [HAT]), creating 12 treatments. For example, one treatment was "low rate at 24 HAT". Each treatment had five replicates, making 60 arenas (experimental units). All arenas were sprayed prior to slug introduction and on the same day, 26 Jun. 2016. A $750 \mathrm{ml}$ aluminum spray bottle was used to spray corn plants until runoff, then arenas were stored uncovered in a greenhouse. Five A. subfuscus were added to each treated arena at the specified time interval (HAT). After slugs were added, arenas were covered with a partially mesh plastic lid. Slugs remained in arenas for $12 \mathrm{~h}$, then were transferred to recovery cups. After $48 \mathrm{~h}$ in recovery cups, A. subfuscus were assessed for mortality as described in the exposure experiment.

Wetting event after sprays. Two additional residue toxicity experiments were conducted with the addition of overhead misting following sprays. Environmental moisture resulting in accumulated water on plant surfaces (e.g., dew or rain) is necessary to provoke slug activity, so we hypothesized that wetting methomyl-treated plants may detoxify residues. The first wetting experiment was a three by three factorial. Treatments included all combinations of each solution (check, high rate, and low rate) and time interval after treatment (12, 24, 48 HAT), creating nine treatments. Each treatment had five replicates, making 45 arenas (experimental units). All experimental units received a "wetting event" 6 HAT, in which plants were misted by a greenhouse irrigation system $1.5 \mathrm{~m}$ above arenas, achieving slight accumulation of water droplets on corn blades without washing (ca. $0.3 \mathrm{~cm}, 1 \mathrm{~min}$ runtime). Sprays occurred on 12 Jul 2016. All other methods (sprays, slug addition, storage, and mortality rating) were the same as the previous residue toxicity experiment.

The second wetting experiment incorporated a wetting event into two of four treatments: 1 . Check solution without a wetting event (U); 2 . Check solution followed by a wetting event (UW); 3. High rate methomyl solution without a wetting event $(\mathrm{H})$; and 4 . High rate methomyl solution followed by a wetting event (HW). All other experimental procedures were performed the same as described in the previous wetting experiment. This experiment was performed twice (two "runs"). Sprays were applied for the first run on 20 July and for the second on 26 July 2016. The first run examined mortality at post treatment intervals 12, 24, 48 and 96 HAT; the second at 12, 24, 48, 96, and 144 HAT.

Repellency. The final experiment tested if $A$. subfuscus was repelled by methomyl-treated corn plants. Arenas were constructed from rectangular plastic food storage containers, $24.9 \times 18.3 \mathrm{~cm}$ opening and $18 \mathrm{~cm}$ tall, with $7 \mathrm{~cm}$ of soil and 20 live corn plants. Arenas were split in half so that 10 corn plants were concentrated on each end, leaving an $8 \mathrm{~cm}$ strip of bare soil in the center. Corn on one half of all arenas received the check solution, and corn on the other half was assigned an experimental treatment solution (check, low rate, or high rate). Treatments were: 1 . 'Check', check solution vs. check solution; 2 . 'Low rate' low rate solution vs. check solution; and 3. 'High rate', high rate solution vs. check solution. Solutions were applied with $750 \mathrm{ml}$ aluminum spray bottles. To block solution drift outside the treatment zone, a metal sheet was held between the plants and center soil strip while sprays were applied. Two nearly identical experiments were conducted, with the only difference being that six $A$. subfuscus were used per arena for the first experiment (30 A. subfuscus per treatment) and five for the second (25 A. subfuscus per treatment). Slugs for the first experiment were collected on 13 Aug. 2016, and the second on 16 Aug. 2016. There were five replicates of each experimental treatment (15 arenas per experiment). Slugs were introduced into arenas 6 HAT on open Petri dishes set on the untreated soil strip in the center of each arena. Twenty-four $\mathrm{h}$ after release, A. subfuscus were counted on each side of arenas.

Data Analysis. Data were analyzed in SAS 9.4 (SAS, 2020). For all analyses, significant differences were accepted when $P<0.05$. For experiments in which percentage mortality was the response variable, an arcsine square root transformation was used for analysis (results are displayed as percentage mortality). For exposure method and residual toxicity experiments, percentage mortality was the response variable. For the exposure method experiment, a General Linear Model was used via 'Proc Glimmix' to detect significant differences among exposure methods (independent variable), followed by a Tukey's HSD to separate treatment averages. For residual toxicity experiments, independent variables were spray solution (check, high rate, low rate), time interval (HAT), and their interaction. Average mortality percentages among treatment were analyzed for differences using General Linear Mixed 


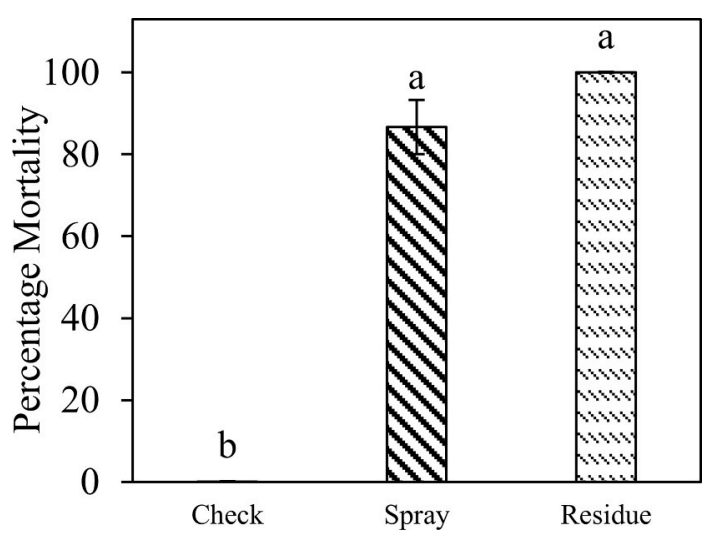

Fig. 1. Bars are average percentage of A. subfuscus killed ( \pm SEM) for the following treatments: 1 . Check: exposure to check solution delivered via direct spray and residue contact; 2. Spray: exposure to high rates of methomyl via topical spray applications; 3. Residue: exposure to high rates of methomyl via dried residues on corn plants. Bars not sharing a letter are significantly different $(P<0.05)$ according to Tukey's HSD.

Models via 'Proc Glimmix'. The solution, post-spray interval, and interaction were fixed effects. For the residue decline experiments incorporating wetting into treatments, both runs were examined in a single analysis using 'run' as a blocking factor (random effect). Time and treatment mortality averages were separated using Tukey's HSD. For the repellency experiments, both runs were performed as a single analysis. Percentages of $A$. subfuscus on experimental solution sides were the response variables. Repellency was determined for individual treatments by conducting two tailed t tests via 'Proc Ttest'; $\mathrm{H}_{\mathrm{a}}$ (repellency) for each treatment was accepted if significantly $>50 \%$ of slugs were found on the check solution side (Zar, 2010).

\section{Results and discussion}

A. subfuscus mortality resulting from contact with methomyl sprays and residues were significantly greater than the check $\left(\mathrm{F}_{2,10}=136.4, P\right.$ $<0.001$ ), achieving 86.7 and 100 percent mortality, respectively (Fig. 1). There was no difference between the two methomyl exposure methods and, therefore, this is not likely the cause of poor commercial efficacy.

For the residue decline experiment without a post-spray wetting event, all fixed effects (post-treatment interval [HAT], solution [check, low rate, and high rate], and their interaction) significantly affected
A. subfuscus mortality $\left(\mathrm{F}_{3,44}=23.2, P<0.001 ; \mathrm{F}_{2,44}=423.6, P<0.001\right.$; $\mathrm{F}_{6,44}=8.0, P<0.001$; respectively). Residues from high and low rates remained significantly toxic to $A$. subfuscus through $96 \mathrm{HAT}$, although at 96 HAT there was a significant decline in mortality in both (Fig. 2A). For the second residue decline experiment in which all arenas received a post treatment wetting event, all fixed effects (post-treatment interval, solution, and their interaction) significantly affected $A$. subfuscus mortality $\left(\mathrm{F}_{1,20}=27.0, P<0.001 ; \mathrm{F}_{2,20}=9.2, P=0.002 ; \mathrm{F}_{2,20}=7.07, P=\right.$ 0.005 ; respectively). Average mortality from both high and low rates was $36 \%$ at $12 \mathrm{HAT}$, and decreased to $0 \%$ and $5 \%$ at $24 \mathrm{HAT}$ for low and high rates, respectively. At $48 \mathrm{HAT}$, all solutions resulted in $0 \%$ mortality (Fig. 2B).

In the residue decline experiment with wetting as a treatment factor, all fixed effects, (post-treatment interval, methomyl/wetting, and their interaction) significantly affected $A$. subfuscus mortality $\left(\mathrm{F}_{3,127}=15.1\right.$, $P<0.001 ; \mathrm{F}_{3,127}=431.0, P<0.001 ; \mathrm{F}_{9,127}=7.89, P<0.001 ;$ respectively). Addition of wetting to high rate methomyl (HW) reduced A. subfuscus mortality by ca. $50 \%$ at $12 \mathrm{HAT}$, ca. $71 \%$ at $24 \mathrm{HAT}$, and $100 \%$ at 48 HAT and beyond compared to the high rate methomyl treatment without wetting (Fig. 3). High rate without wetting $(\mathrm{H})$ was at or near $100 \%$ mortality through 48 HAT and only dropped to $76 \%$ mortality at 96 HAT. In second experimental run, the high rate methomyl without wetting $(\mathrm{H})$ remained significantly toxic to 144 HAT $\left(F_{3,9}=65.7, P<0.001\right)$, achieving about $80 \%$ mortality, while all other treatments produced $0 \%$ mortality. Greater than 96 HAT was only examined in the second run.

Results from residue decline experiments demonstrated that methomyl can remain significantly toxic to A. subfuscus for up to 144 HAT in dry laboratory conditions; however, a minor wetting event resembling a heavy dew can cause a rapid decline in toxicity to A. subfuscus. Because slugs only emerge when ambient moisture is high, this is a likely factor reducing field efficacy of methomyl against slugs.

Pooled data from the two repellency experiments showed an average of $31.7 \%$ of $A$. subfuscus occupied high rate side in the high rate vs. check treatment arenas, which was significantly less $(t=-2.38, d f=9, P=$ 0.04 ) than $50 \%$, suggesting a repellent effect (Fig. 4). No differences in side occupancy occurred in low rate vs. check, or check vs. check treatments. These results suggested that plants treated with high rate concentrations of methomyl may cause minor repellency of slugs, which implies that repellency may be a minor factor affecting field efficacy of methomyl against slugs. However, this outcome was narrowly significant for only high rates, so repellency is likely a less important mechanism than ambient moisture.

In conclusion, our study provides a plausible explanation for
(A)

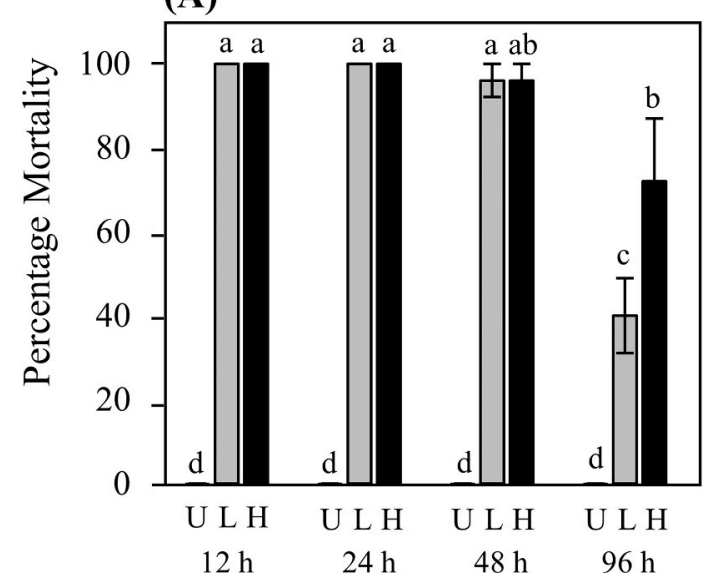

(B)

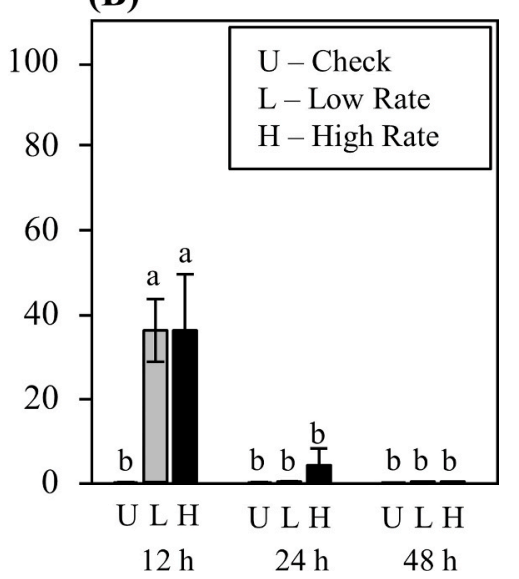

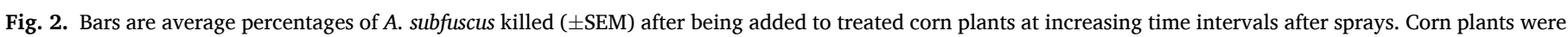

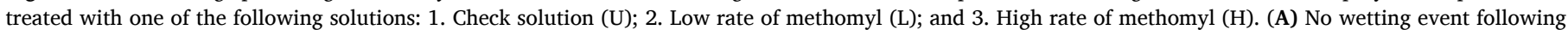

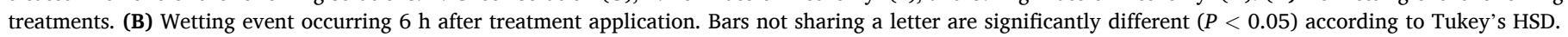




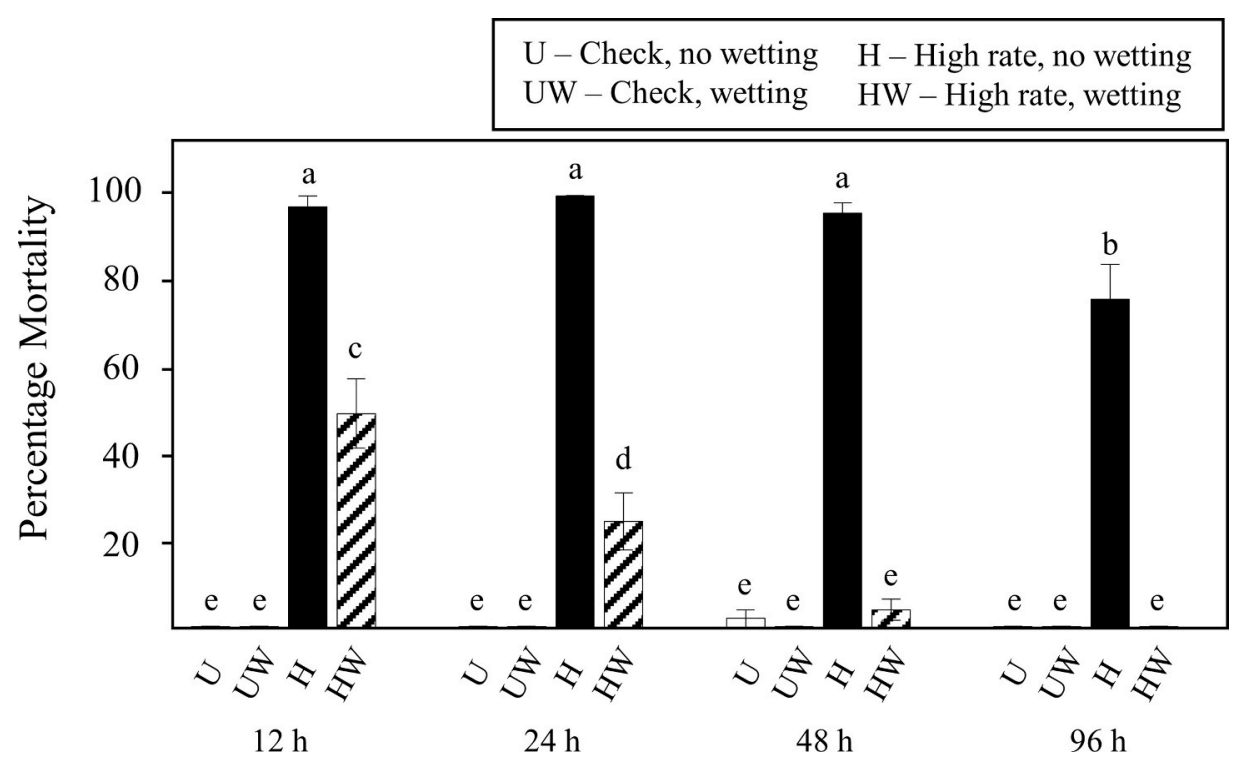

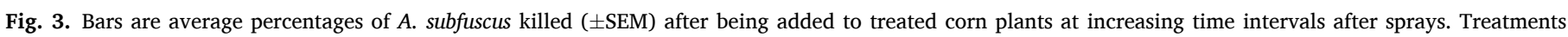

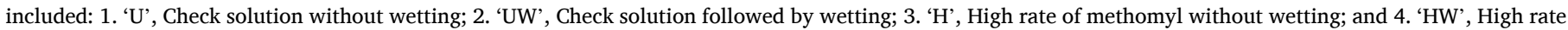
of methomyl followed by wetting. Bars not sharing a letter are significantly different $(P<0.05)$ according to Tukey's HSD.

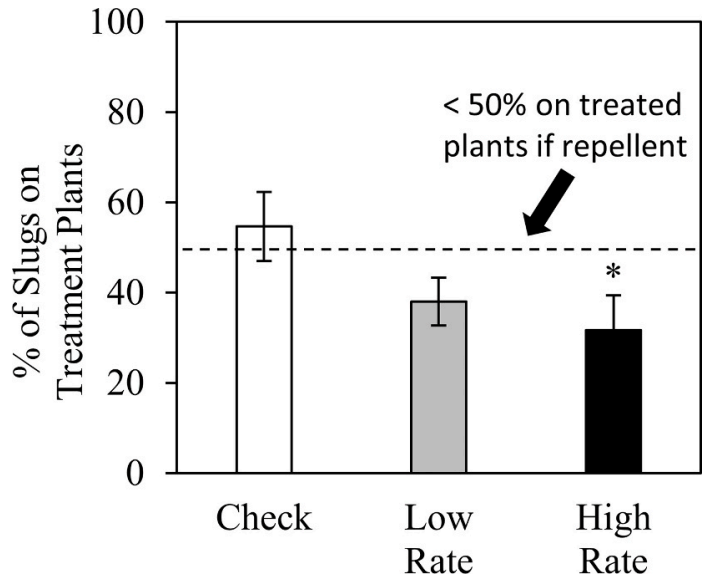

Fig. 4. Average percentage of $A$. subfuscus ( \pm SEM) found on the experimental solution sides in each treatment: 1 . 'Check', check solution vs. check solution; 2. 'Low rate' low rate solution vs. check solution; and 3. 'High rate', high rate solution vs. check solution. Bars with * had significantly fewer than $50 \%$ of A. subfuscus on the experimental solution side, indicating repellency.

methomyl's poor control of slugs in the field despite high efficacy in lab trials. Under low ambient moisture conditions, methomyl residues on corn plants remained stable and toxic to slugs for many days, but small accumulations of water on methomyl-treated plants triggered a rapid decline in toxicity. In the field, slugs will remain in protected moist areas until a wetting event occurs (Godan, 1983; Douglas and Tooker, 2012). Therefore, if ambient moisture is high enough to elicit slug activity, it will also detoxify methomyl residues so a lethal dose cannot occur. We did not examine the mechanism that causes moisture to detoxify methomyl, but past research demonstrated that slightly alkaline water (7.5-8.0 pH) rapidly degrades methomyl residues into less-toxic compounds dimethylamine, carbon dioxide and methomyl oxime through the process of hydrolysis (Miles and Oshiro, 1990).

\section{CRediT authorship contribution statement}

Louis B. Nottingham: Conceptualization, Methodology, Validation, Formal analysis, Investigation, Project administration, Data curation,
Writing - original draft, Writing - review \& editing. Thomas P. Kuhar: Conceptualization, Supervision, Visualization, Validation, Project administration, Funding acquisition, Writing - review \& editing, Resources.

\section{Declaration of competing interest}

The authors declare that they have no known competing financial interests or personal relationships that could have appeared to influence the work reported in this paper.

\section{Acknowledgements}

The authors thank Joanna Whalen for providing guidance and perspective on this work. The authors also thank Liz Fread, Adam Formella, and Hallie Harriman for helping collect $A$. subfuscus. This research did not receive any specific grant from funding agencies in the public, commercial, or not-for-profit sectors.

\section{References}

Bailey, S.E.R., 2002. Molluscidical baits for control of terrestrial gastropods. In: Barker, G.M. (Ed.), Molluscs as Crop Pests. CABI Publishing, Wallingford, UK, pp. 33-54.

Barker, G.M., 2002. Molluscs as Crop Pests. CABI Publishing, Wallingford, UK.

Beyer, W.N., Saari, D.M., 1978. Activity and ecological distribution of the slug, arion subfuscus (Draparnaud) (Stylommatophora, Arionidae). Am. Midl. Nat. 100, 359.

Douglas, M.R., Tooker, J.F., 2012. Slug (Mollusca: Agriolimacidae, Arionidae) ecology and management in no-till field crops, with an emphasis on the Mid-Atlantic Region. J. Integr. Pest Manag. 3 (1), C1-C9. https://doi.org/10.1603/ipm11023.

Eshra, E.H., 2014. Toxicity of methomyl, copper hydroxide and urea fertilizer on some land snails. Ann. Agric. Sci. 59 (2), 281-284.

Godan, D., 1983. Pest Slugs and Snail: Biology and Control. Springer-Verlag Berlin Heidelberg.

Gregory, W.W., Musick, G.J., 1976. Insect management in reduced tillage systems. Bull. Entomol. Soc. Am. 22 (3), 302-304. https://doi.org/10.1093/besa/22.3.302.

Hammond, R.B., Smith, J.A., Beck, T., 1996. Timing of molluscicide applications for reliable control in no-tillage field crops. J. Econ. Entomol. 89, 1028-1032.

Hammond, R.B., Stinner, B.R., 1987. Seedcorn maggots (Diptera: Anthomyiidae) and slugs in conservation tillage systems in Ohio. J. Econ. Entomol. 80 (3), 680-684. https://doi.org/10.1093/jee/80.3.680.

Judge, F.D., Kuhr, R.J., 1972. Laboratory and field screening of granular formulations of candidate molluscicides. J. Econ. Entomol. 65, 242-243.

Miles, C.J., Oshiro, W.C., 1990. Degradation of methomyl in chlorinated water. Environ. Toxicol. Chem. 9 (5), 535-540. https://doi.org/10.1002/etc.5620090501. 
SAS, 2020. Statistical analysis institute. SAS/Stat User's Guide, Release v 9.4 Edition. SAS/Institute, Inc., Cary, NC.

Whalen, J., Cissel, J., Sylvester, P., 2013. Insect management reports: chemical management of slugs in no-till corn and soybean systems. University of Delaware Extension and Newark, Cooperative Extension. In: Insect Management Reports.
University of Delaware, Newark, DE, pp. 6-14. https://www.udel.edu/content/da $\mathrm{m}$ /udelImages/canr/pdfs/extension/sustainable-agriculture/pest-management/ 2013-Insect-Management-Trials.pdf, 11/16/2020.

Zar, J.H., 2010. Biostatistical Analysis, fifth ed. Prentice Hall, NJ, pp. 103-106. 